able posts. British Medical Association Treasurer Dr. David Pickersgill said that while Johnson's letter "reflected the Association's agreed position of working towards a pragmatic solution for this year, its tone failed to reflect the anger being currently expressed by members of the Association, particularly junior doctors. It was felt to be insufficiently sensitive and has led to a loss of confidence in the chairman."
Marijuana profiteering: Auditor-General Sheila Fraser has announced that her office is "in the early stages of an audit of certain user fees" associated with Health Canada's medicinal marijuana program. But Fraser cautioned in a letter to New Democrat Member of Parliament Libby Davies that her auditors are not necessarily investigating specific allegations that Health Canada is charging patients marijuana fees that are 15 times higher than

\title{
DISPATCH
}

\section{Canadian dispatches from medical fronts: Fort McMurray}

I $\mathrm{n}$ the minds of many, being a boomtown translates into a run on gold faucets and lineups at luxury car dealerships. Nothing could further from the truth, as oilsands capital Fort McMurray is discovering as it attempts to cope with explosive growth, an exorbitantly expensive rental market and acute labour shortages.

Nowhere is the strain more heavily felt than on the health front, which now annually turns over $40 \%$ of hospital and public health staff and now has a $20 \%$ vacancy rate for posted positions.

Officially, $30 \%$ of the population has no family doctor, roughly double the national average. Unofficially, that excludes the ever-present construction workforce, so the true rate probably approaches $44 \%$. Only 2 of I4 family physicians serving 82 ooo people in the 64000 square kilometre surrounding area still accept patients.

The ratio of 0.17 family physicians per 1000 population is one-sixth that of Edmonton, 435 kilometres to the south.

The local emergency room, the third busiest in the province, can't functionally accommodate more than I physician at a time. A record 156 patients were recently seen during a I2-hour shift.

In January, family physicians gave notice that they would no longer stretch themselves to cover the "Doc of the Day" schedule for hospitalized patients without family doctors, so the government implemented a \$1200 daily feefor-service (plus fee) temporary rotation of out-of-town doctors.

Patients, though, have been left with nowhere to go when discharged, and continuity of care has been compromised. Local family doctors interested in providing some coverage found themselves unilaterally excluded from the plan, fueling a sense of alienation. Still, in response, the government has appointed a transition team, so there is hope of restitution and restoration. Michel Sauve MD MSc, Fort McMurray

CMAJ is pleased to launch a new section "Canadian dispatches from medical fronts," in which physicians and other health care providers can provide eyewitness glimpses of the medical front, whether defined by location or intervention. Without intending to restrict options, the front can be defined as any unique confluence of time and event, whether in developing countries, war zones, inner-city clinics, in the North, or with a novel surgical technique or intervention. The frequency of the section will be conditional on submissions, which must run to a maximum 350 words or be subject to our ruthless editorial pencils. Forward submissions to: Wayne.Kondro@cma.ca

DOI:I0.1503/cmaj.070516

the department pays for the weed. Davies had requested an audit while accusing Health Canada of "bankrupting" people with chronic pain. The audit also followed the launch of a court challenge from the Vancouver Island Compassion Society alleging that the medicinal marijuana program is failing to meet the constitutional rights of critically and chronically ill Canadians.

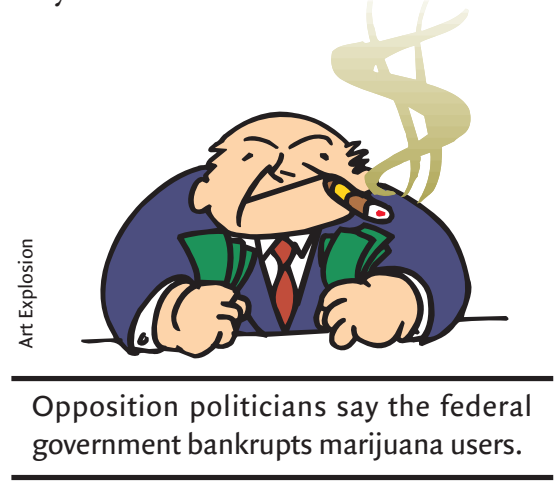

Global deaths: Mortality rates for communicable, maternal, perinatal and nutritional causes will decline over the next few decades, except for HIV/AIDS, according to the World Health Organization's annual World Health Statistics report. Noncommunicable conditions are projected to cause $70 \%$ of all deaths by 2030, during which the 4 leading causes of death globally are expected to be ischaemic heart disease, stroke, HIV/AIDS and chronic obstructive pulmonary disease. World Health Statistics 2007 is available at http://www.who.int/whosis

It's a wrap: The World Health Assembly wrapped up its 6oth session by adopting a resolution requiring the World Health Organization and its 193 member states to establish an international stockpile of vaccines for $\mathrm{H}_{5} \mathrm{NI}$ and influenza viruses that might result in pandemics. The resolution also binds the World Health Organization to "formulate mechanisms and guidelines aimed at ensuring fair and equitable distribution of pandemic-influenza vaccines at affordable prices in the event of a pandemic." The Assembly also approved a nearly US\$900 million increase, to $\$ 4.2$ billion, in the World Health Organization's budget for 2008/09. - Wayne Kondro, CMAJ

DOI:Io.I503/cmaj.070749 